Review Article

\title{
An Overview of Transmission Line Protection by Artificial Neural Network: Fault Detection, Fault Classification, Fault Location, and Fault Direction Discrimination
}

\author{
Anamika Yadav and Yajnaseni Dash \\ Department of Electrical Engineering, National Institute of Technology, Raipur 492010, India \\ Correspondence should be addressed to Anamika Yadav; ayadav.ele@nitrr.ac.in
}

Received 28 August 2014; Revised 10 December 2014; Accepted 10 December 2014; Published 28 December 2014

Academic Editor: Chao-Ton Su

Copyright (c) 2014 A. Yadav and Y. Dash. This is an open access article distributed under the Creative Commons Attribution License, which permits unrestricted use, distribution, and reproduction in any medium, provided the original work is properly cited.

Contemporary power systems are associated with serious issues of faults on high voltage transmission lines. Instant isolation of fault is necessary to maintain the system stability. Protective relay utilizes current and voltage signals to detect, classify, and locate the fault in transmission line. A trip signal will be sent by the relay to a circuit breaker with the purpose of disconnecting the faulted line from the rest of the system in case of a disturbance for maintaining the stability of the remaining healthy system. This paper focuses on the studies of fault detection, fault classification, fault location, fault phase selection, and fault direction discrimination by using artificial neural networks approach. Artificial neural networks are valuable for power system applications as they can be trained with offline data. Efforts have been made in this study to incorporate and review approximately all important techniques and philosophies of transmission line protection reported in the literature till June 2014. This comprehensive and exhaustive survey will reduce the difficulty of new researchers to evaluate different ANN based techniques with a set of references of all concerned contributions.

\section{Introduction}

There is no fault-free system and it is neither practical nor economical to build a fault-free system. The various cases of abnormal circumstances such as natural events, physical accidents, equipment failure, and misoperation generate faults in the power system. The consequences of faults are traumatic amplification of current flow, increasing heat produced in the conductors leading to the major cause of damage. The actual magnitude of fault depends on resistance to flow and varied impedance between the fault and the source of power supply. Total impedance comprises of fault resistance, resistance and reactance of line conductors, impedance of transformer, reactance of the circuit, and impedance of generating station. The conventional distance relay settings are based on a predetermined network configuration with worst fault outcomes [1-6]. As the neural network based algorithm has more adaptability and is likely to be more accurate, various researchers used it for power system protection which is the main focus of this study. A number of prime purposes and applications of ANN are accessible in the literatures; those will assist to recognize the perception of accepting it as a tool for fault detection, classification, and localization on transmission line of the power systems. Various journals, conference papers, books, online libraries, and databases were researched and reviewed for gathering proper information to develop a broad insight and comprehension of the subject being studied. Both scholarly and nonscholarly articles were surveyed and considered from databases like IEEE, Scopus, Google Scholar, Academia Search Premier, Pro-Quest, EBSCO, and other relevant websites.

The paper is organized as follows. In Sections 2 and 3, a brief introduction of power system faults and artificial neural networks is provided, Section 4 is about distance protection by ANN method; in Section 5, ANN and its application for protecting transmission line are illustrated. Section 6 deals with the conclusions drawn from this survey followed by acknowledgments and references. 


\section{Faults in Power System}

Fault is an unwanted short circuit condition that occurs either between two phases of wires or between a phase of wire and ground. Short circuit is the most risky fault type as flow of heavy currents can cause overheating or create mechanical forces which may damage equipments and other elements of power system [1-6].

2.1. Categories of Faults. Faults also can be classified into three types, that is, symmetrical faults, unsymmetrical faults, and open circuit faults.

2.1.1. Symmetrical Faults. The fault that results in symmetrical fault currents (i.e., equal currents with 120 displacements) is known as a symmetrical fault. Three-phase fault is an example of symmetrical fault where all three phases are short circuited with or without involving the ground.

2.1.2. Unsymmetrical Faults. Examples of different unsymmetrical faults are single phase to ground, two phases to ground, and phase to phase short circuits. The details of these shunt fault types that can occur in transmission line are described as follows.

(1) Single Phase to Ground (L-G) Fault. L-G is a short circuit between any one of phase conductors and earth (prevalence is $70 \%-80 \%)$. It may be caused either by insulation failure between a phase conductor and earth or breaking and falling of phase conductor to the ground.

(2) Two Phases to Ground ( $L-L-G$ ) Fault. L-L-G is a short circuit between any two phases and earth (prevalence is $10 \%-$ $17 \%)$.

(3) Phase to Phase (L-L) Fault. L-L is a short circuit between any two phases of the system (prevalence is $8 \%-10 \%$ ).

(4) Three-Phase (L-L-L) Fault. L-L-L is a short circuit between any two phases of the system (prevalence is $2 \%-3 \%$ ).

2.2. Open Circuit Faults. This type of fault is caused by breaking of conducting path. Such fault occurs when one or more phases of conductor break or a cable joint/jumper (at the tension tower location) on an overhead line fails. Such situations may also arise when circuit breakers or isolators open but fail to close in one or more phases. During the open circuit of one of the two phases, unbalanced current flows in the system, thereby heating rotating machines. Protective schemes must be provided to deal with such abnormal conditions.

\section{Artificial Neural Network}

Artificial neural network (ANN) has been equipped with distinctiveness of parallel processing, nonlinear mapping, associative memory, and offline and online learning abilities. The wide uses of ANN with its conquering outcomes make it

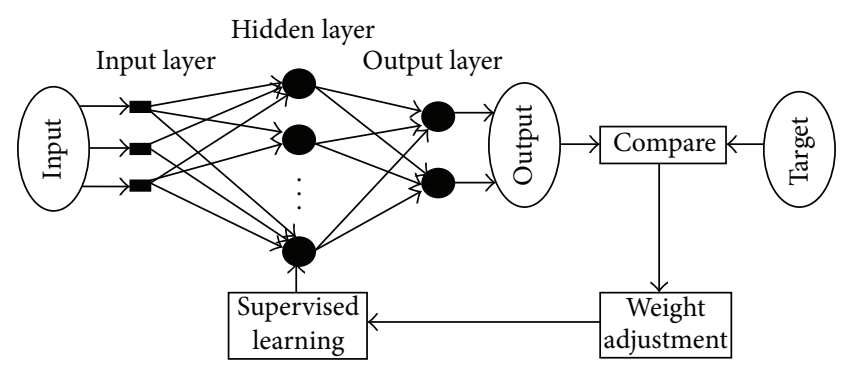

FIGURE 1: Supervised architecture of ANN.

an effective diagnostic mean in electric power systems. Its versatility with multitude applicability can be seen in other areas of science and engineering research [7-9]. It is a complex network of interconnected neurons where firing of electrical pulses via its connections leads to information propagation. ANN is trained by using prior chosen fault samples as input and set of fault information as output for fault diagnosis application. Neural networks are comprised of primarily three basic learning algorithms such as supervised learning, unsupervised learning, and reinforced learning. Among these supervised learning is most commonly used and is also referred to as learning with a teacher. This is applied when the target is having identified value and is associated with each input in the training set [7]. Figure 1 represents the supervised architecture of ANN.

Error back propagation (BP) neural network was applied by Chan [10] for diagnosis of fault in power system. However slow speed training and the shortcomings of local optima lead to the introduction of additional momentum factor for problem solving. Radial basis function (RBF) neural network has a faster learning speed and the ability of arbitrary function approximation. Bi et al. presented a novel RBF neural network for estimating section of fault. Their simulation results of 4bus test system shown that the capability of RBF neural network in grid fault diagnosis was better than the conventional BP neural net [11].

For solving improper problems, neural network topologies are to be altered and there is a need to retrain the network. Cardoso et al. [12] used the true capacity of multilayer perception (MLP) and generalized regression neural network (GRNN) for fault estimation in electric power system. GRNN is having the advantage of faster learning, global optimum, and lower requirement of comprehensive sample. They fed the failure information into MLP and the resultant outcome was given as output to GRNN. They also compared ANN fault diagnosis methods with expert system diagnostic methods and found that ANN based methods may evade the formation of expertise, expert heuristic knowledge, and expression and hence save tedious work.

\section{Distance Protection by ANN}

The fundamental principle of distance protection is that the apparent impedance seen by the relay reduces considerably in case of line fault. A fault is indicated if the ratio of apparent impedance to the positive sequence impedance is less than 
unity. This scheme of protection is inherently directional and used by impedance and Mho relays. This paper focuses upon the studies of distance protection scheme applying ANN approach.

Adaptive relaying was introduced for widespread applications including incorrect or fault operations measurement. The learning capacity of ANN from input and output patterns extended its applicability in several adaptive protection schemes. Khaparde et al. [13] applied adaline neural network model in offline mode for protective relaying operation of transmission lines. They also proposed adaptive distance protection by using ANN [14]. They have applied MLP model to reduce misoperation of a relay. Girgis et al. [15] presented a method for the computation of fault location in twoand three-terminal high voltage lines which is based on digital computation of the three-phase current and voltage $60 / 50 \mathrm{~Hz}$ phasors at the line terminals. For evaluation of the convergence and distinctive solution, this method was tested by electromagnetic transient (EMPT) generated transient data from a steady state fault analysis. Qi et al. [16] proposed ANN approach for distance protection of power system by taking trained data from simulation of a simple power system under load and fault conditions. According to them conventional distance relays might not function properly under certain conditions such as nonlinear arc resistance, high impedance fault, and variable source impedance. However if such relays are implemented with ANN, such issues can be addressed. Khaparde [17] again proposed an adaptive scheme of distance protection using an artificial neural network. Lai [18] implemented an adaptive protection scheme by ANN approach for classification purpose. They have considered conditions of high impedance fault (hard detection because of minute fault current) and variable source impedance. Coury and Jorge [19] proposed distance protection using ANN for transmission lines utilizing the magnitudes of three-phase voltage and current phasors as inputs. ANN based approach for improving the speed of a differential equation based distance relaying algorithm was developed by Cho et al. [20]. Several researchers illustrated various methodologies for improvements in fault distance computation [21-25].

Venkatesan and Balamurugan [26] developed neural network simulator for identifying the optimum ANN structure necessary to train the data and implement the ANN in hardware. However there is no precise rule for selection of the number of hidden layers and neurons per hidden layer. So it is not certain whether or not the ANN based relay gives the optimum output, for maintaining the integrity of the boundaries of the relay characteristics. Pradhan et al. [27] proposed a high speed distance relaying scheme based on RBF neural network due to its capability of distinguishing faults with data falling outside the training pattern. A sequential procedure for distance protection using a minimal RBF neural network for determining the optimum number of neurons in the hidden layer without resorting to trial and error was illustrated by Dash et al. [28]. Authors [29] trained multilayer feed-forward architecture with two inputs and three-trip or no-trip output signals based approach and used BP technique for three-zone distance protection of transmission lines. The first output was used for main protection of the transmission line section, whereas the other two outputs provide backup protection for the adjacent line sections. The input features extracted by discrete-Fourier transform from the fundamental frequency voltage and current magnitudes.

Santos and Senger [30] developed and implemented of a unique ANN based algorithm for transmission lines distance protection. Their algorithm can be used in any transmission line despite of its configuration or voltage level and also does not require any topology adaptation or parameters adjustment when applied to varied electrical systems. Vaidya and Venikar [31] illustrated an ANN based distance protection scheme for long transmission lines by considering the effect of fault resistance of single line to ground fault type. They have utilized the magnitudes of resistance and reactance as inputs for classifying unknown patterns. A novel distance protection approach for detection and classification stages based on cumulants and neural networks was developed by Carvalho et al. [32].

\section{Application of ANN on Transmission Line Protection}

This section presents the studies on application of ANN for fault detection, classification, location, direction discrimination, and faulty phase selection on transmission line.

5.1. Studies on "Fault Detection and Classification". It is necessary to identify the fault and classify its type with the aim of establishing safety and stability of the power system. Lim and Shoureshi [33] developed ANN based monitoring system for health assessment of electric transmission lines. Their system showed satisfactory performance in fault classification by using both MLP (multilayer perceptron) and ART (adaptive resonance theory) classifiers. A comparative study of different ANN based fault detection and classification schemes [3466] is given in Table 1 highlighting the methods used, their response time, and ANN features along with its accuracy.

5.2. Studies on "Fault Detection and Classification and Location". It is extremely essential to identify and locate the transmission line faults for maintaining the proficient and trustworthy operation of power systems. For estimation of the fault location, there are a number of mathematical and intelligent methods accessible in the literature. However, the broad variations in operating conditions such as system loading level, fault inception instance, fault resistance and dc offset, and harmonics contents in the transient signal of the faulty transmission line give rise to unsatisfactory results.

Amjady [67] diagnosed on line power systems fault by a new expert system. Their diagnostic system can be applicable for single or multiple faults and practically examined with real events on a model power system. Several researches have been carried out to detect, classify, and locate the fault on transmission lines by using neural networks by Oleskovicz et al. [68], Coury et al. [69], Othman et al. [70], Mahanty and Dutta Gupta [71], Gracia et al. [72], Lin et al. [73], Jain et al. [74], Othman and Amari [75], Gayathri and Kumarappan [76], Tayeb and Rhim [77], Jiang et al. [78, 79], Warlyani et al. 


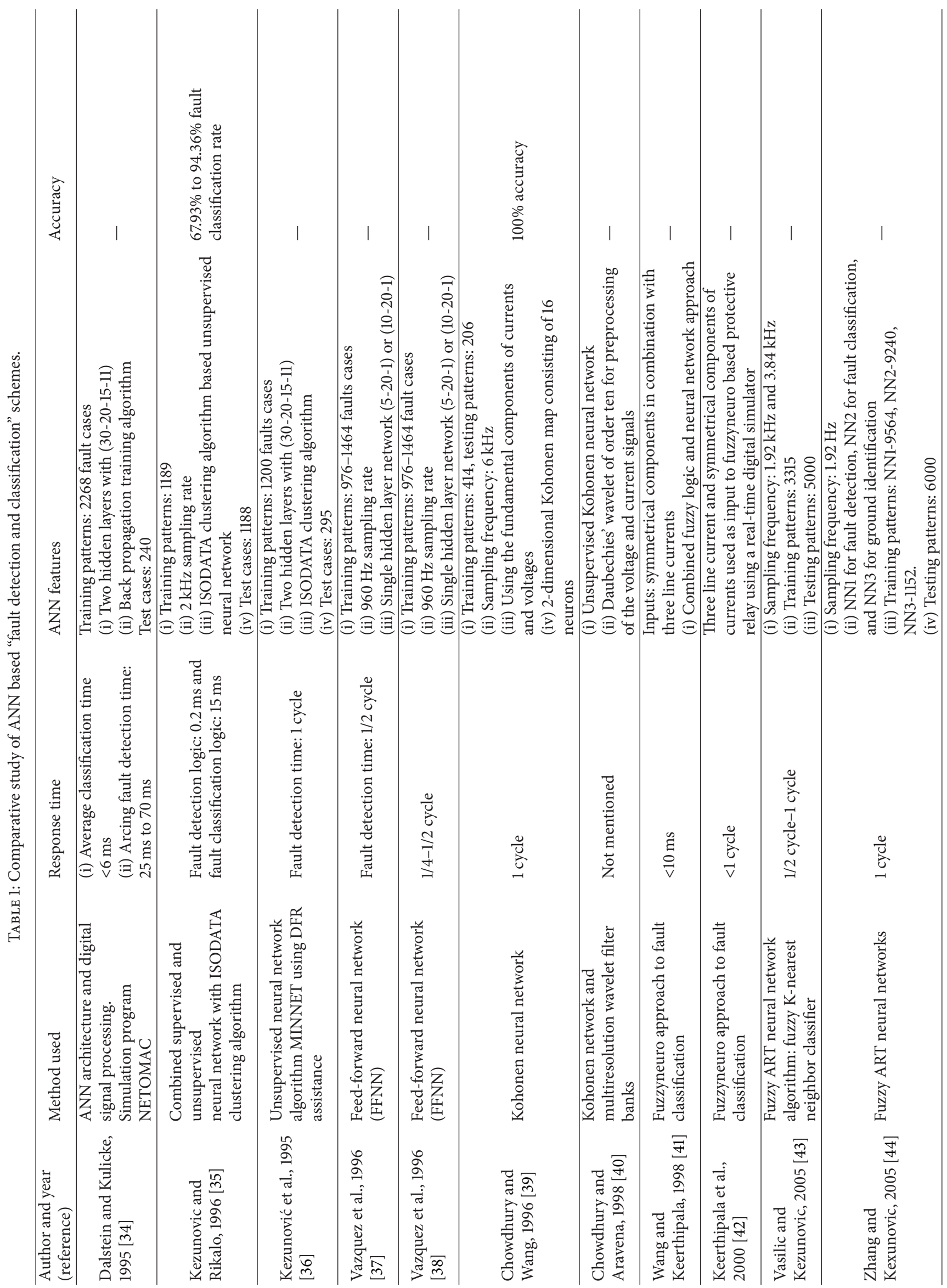




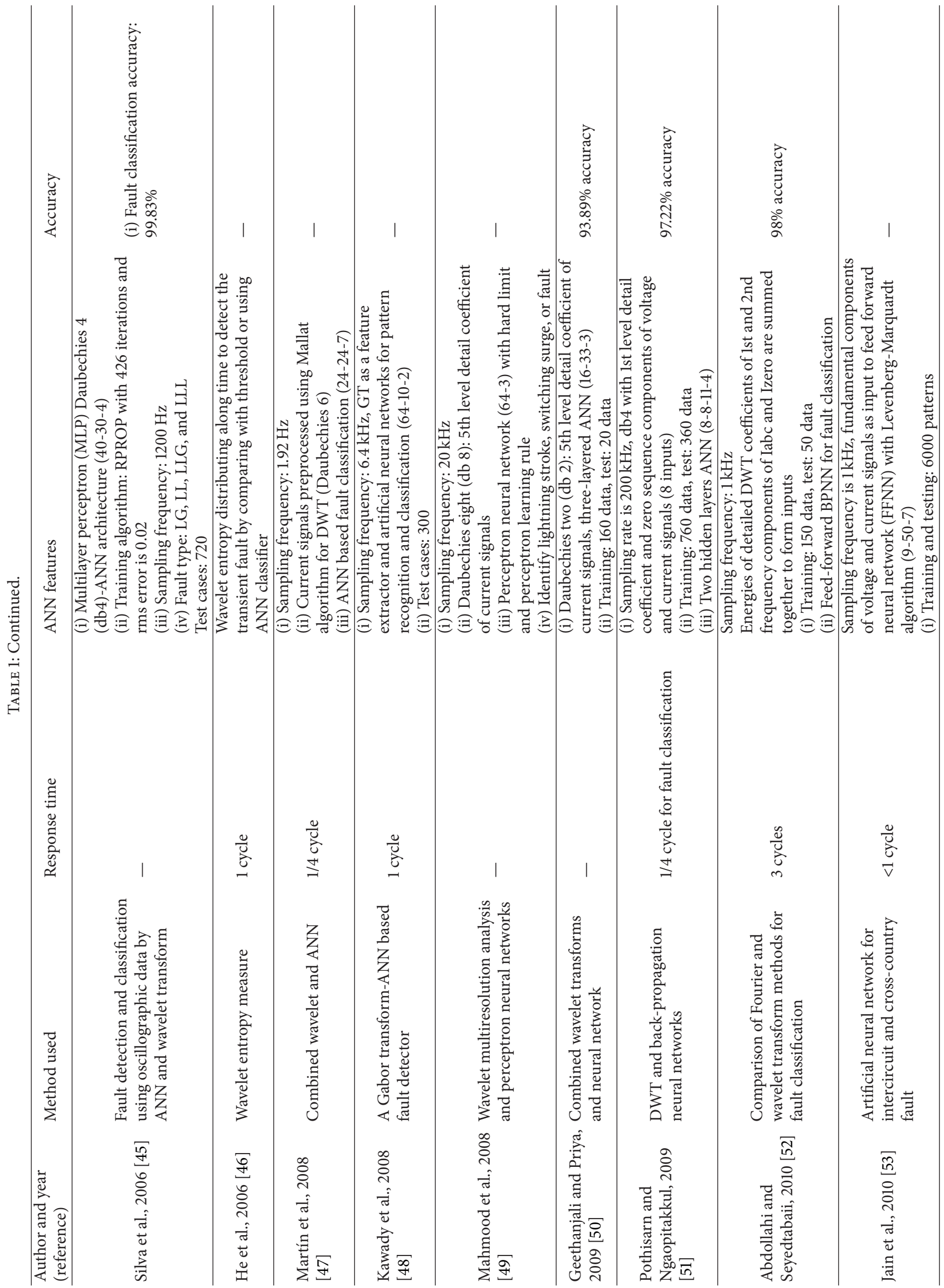




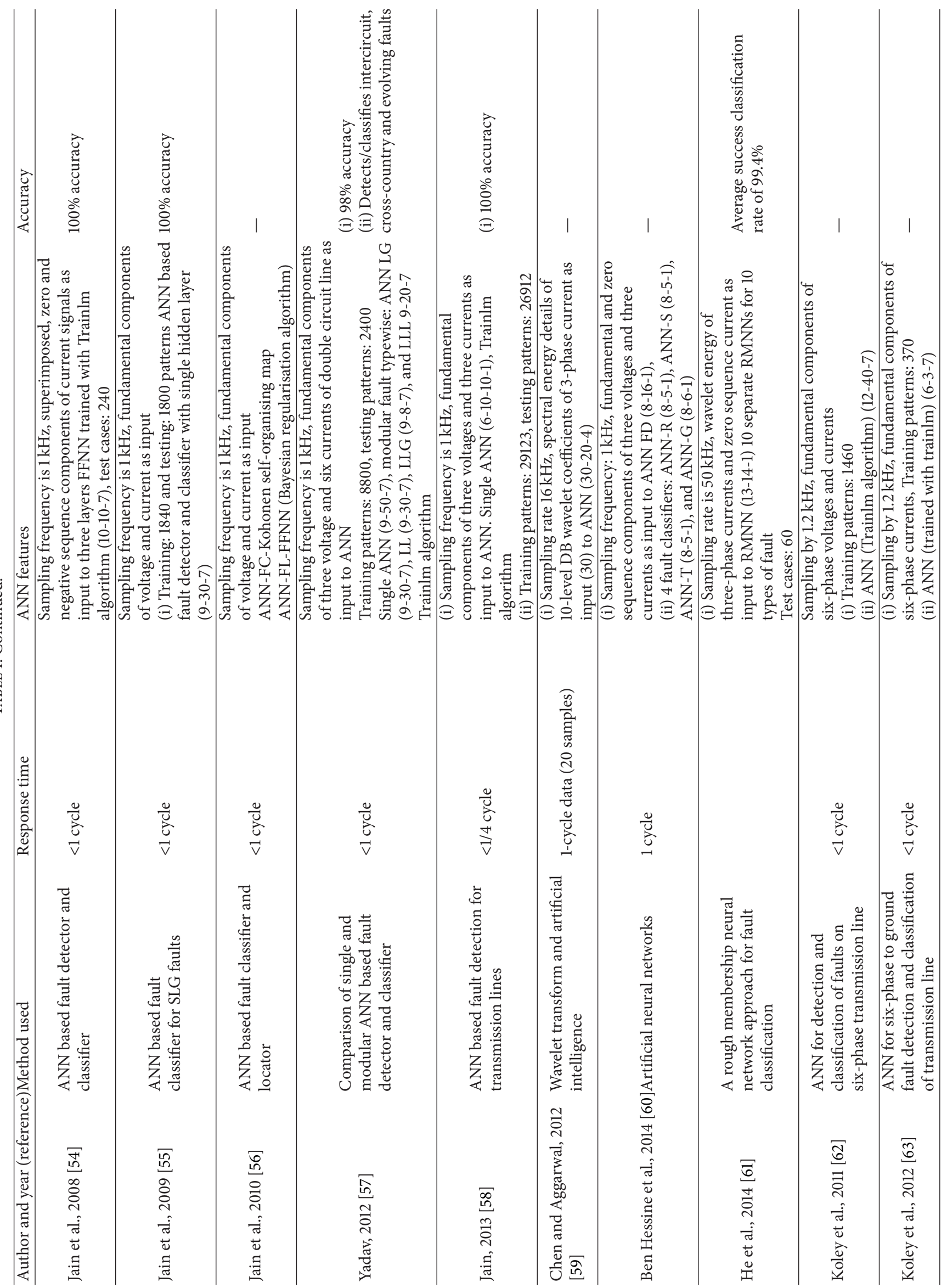




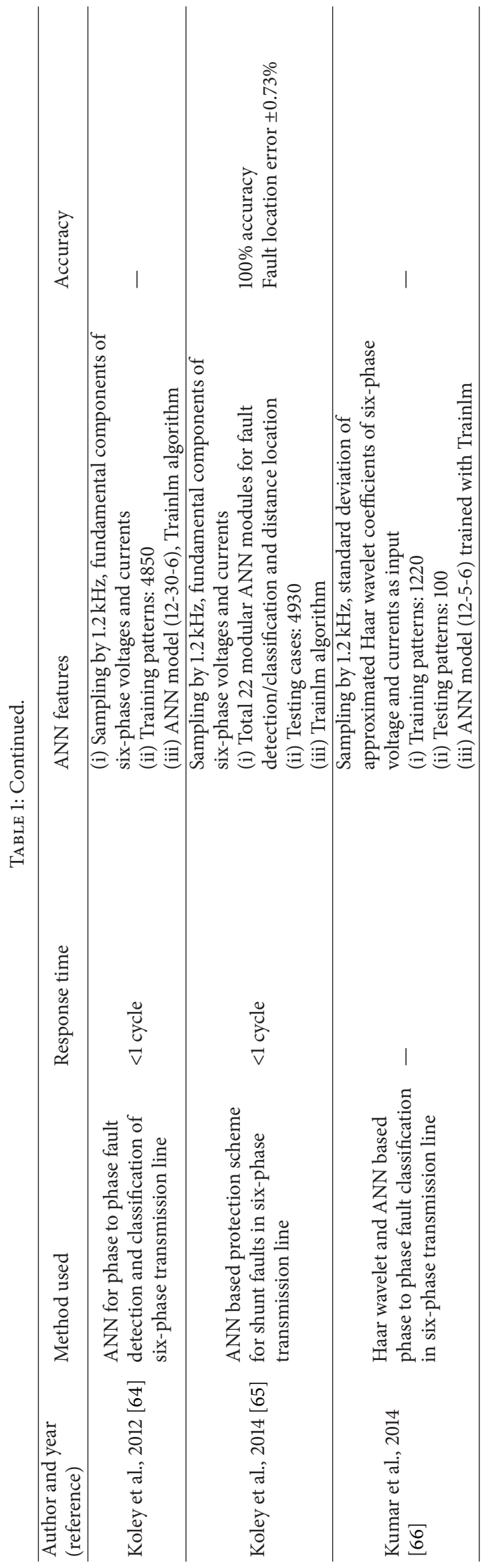




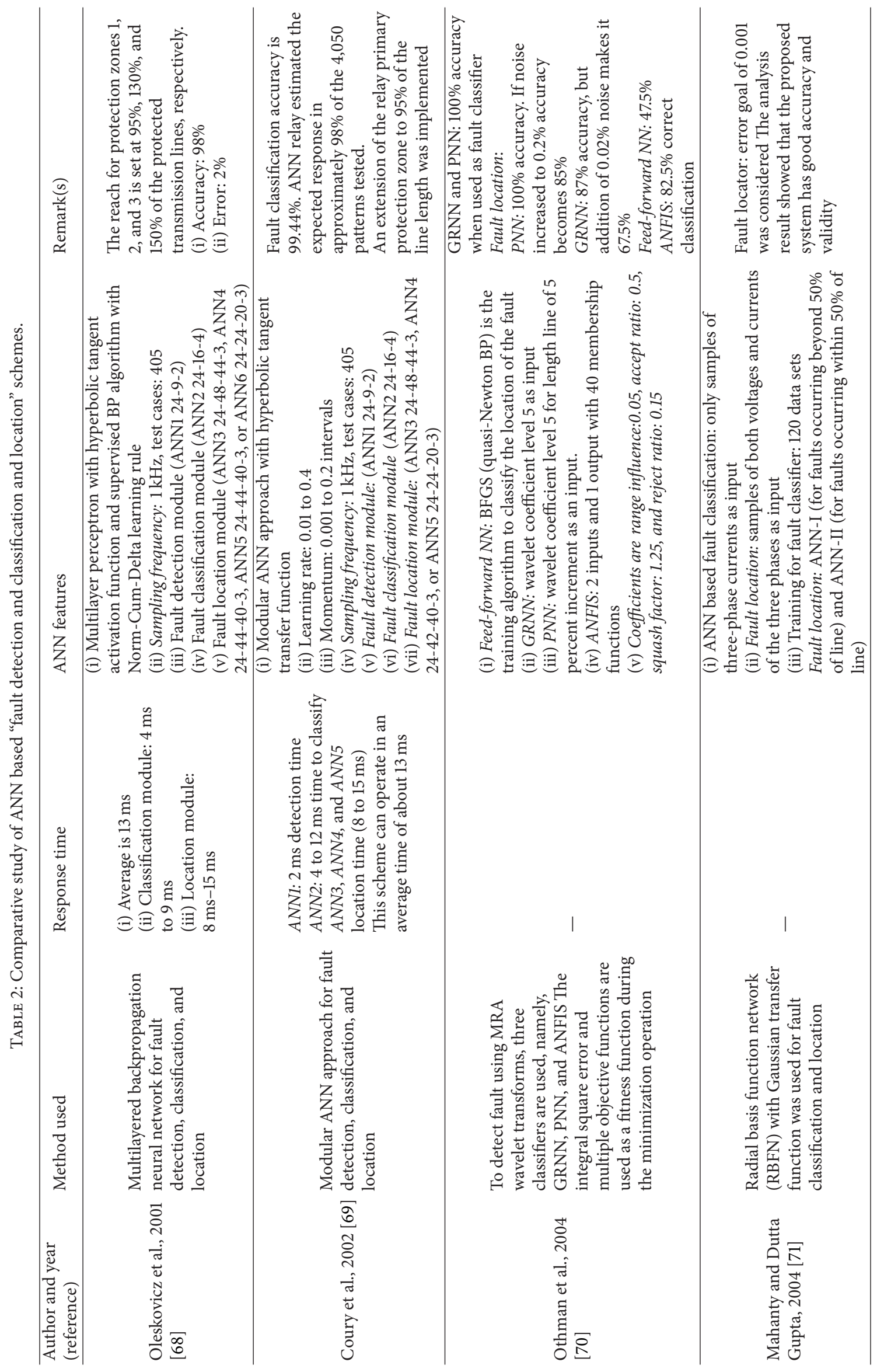




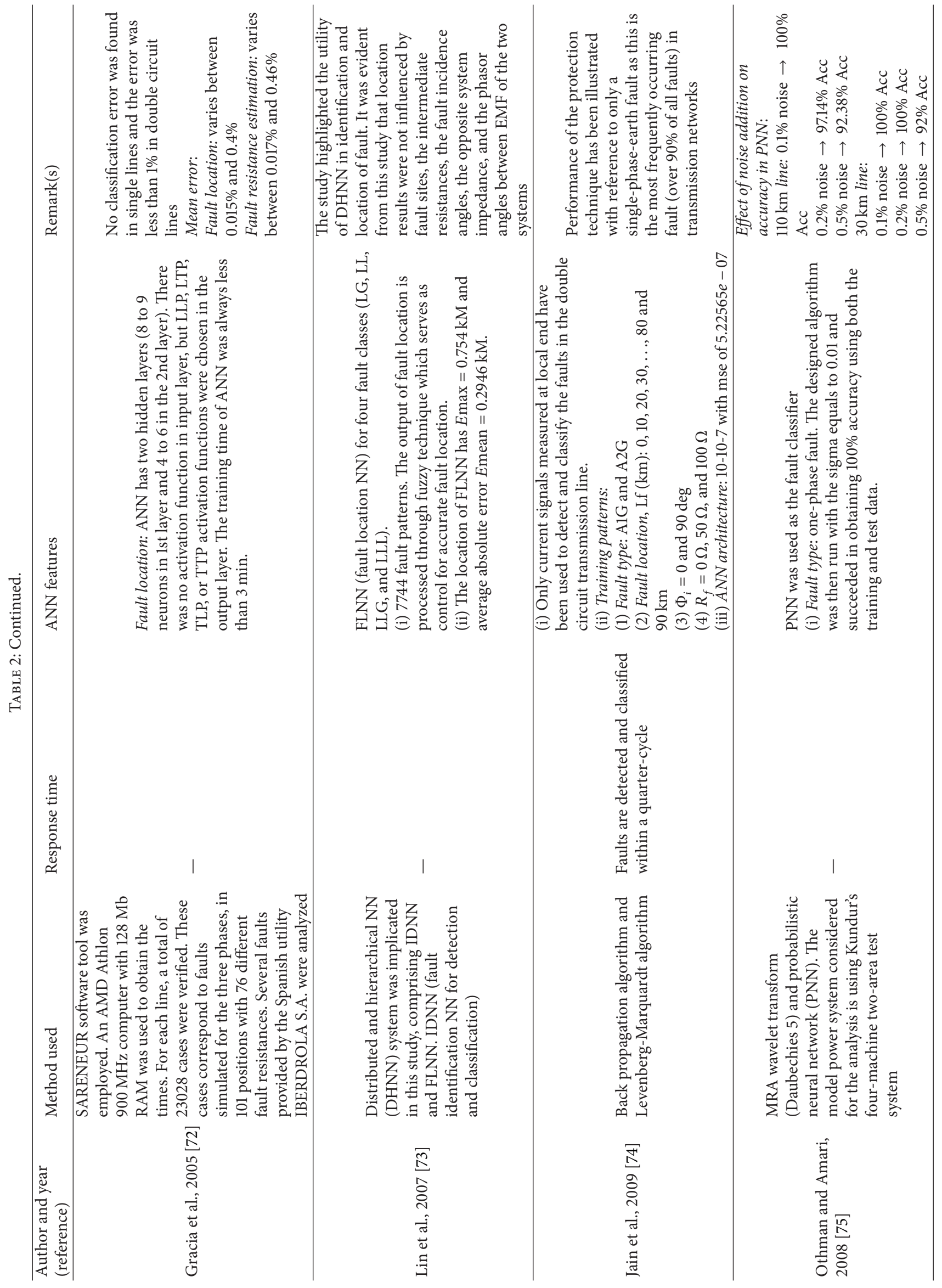




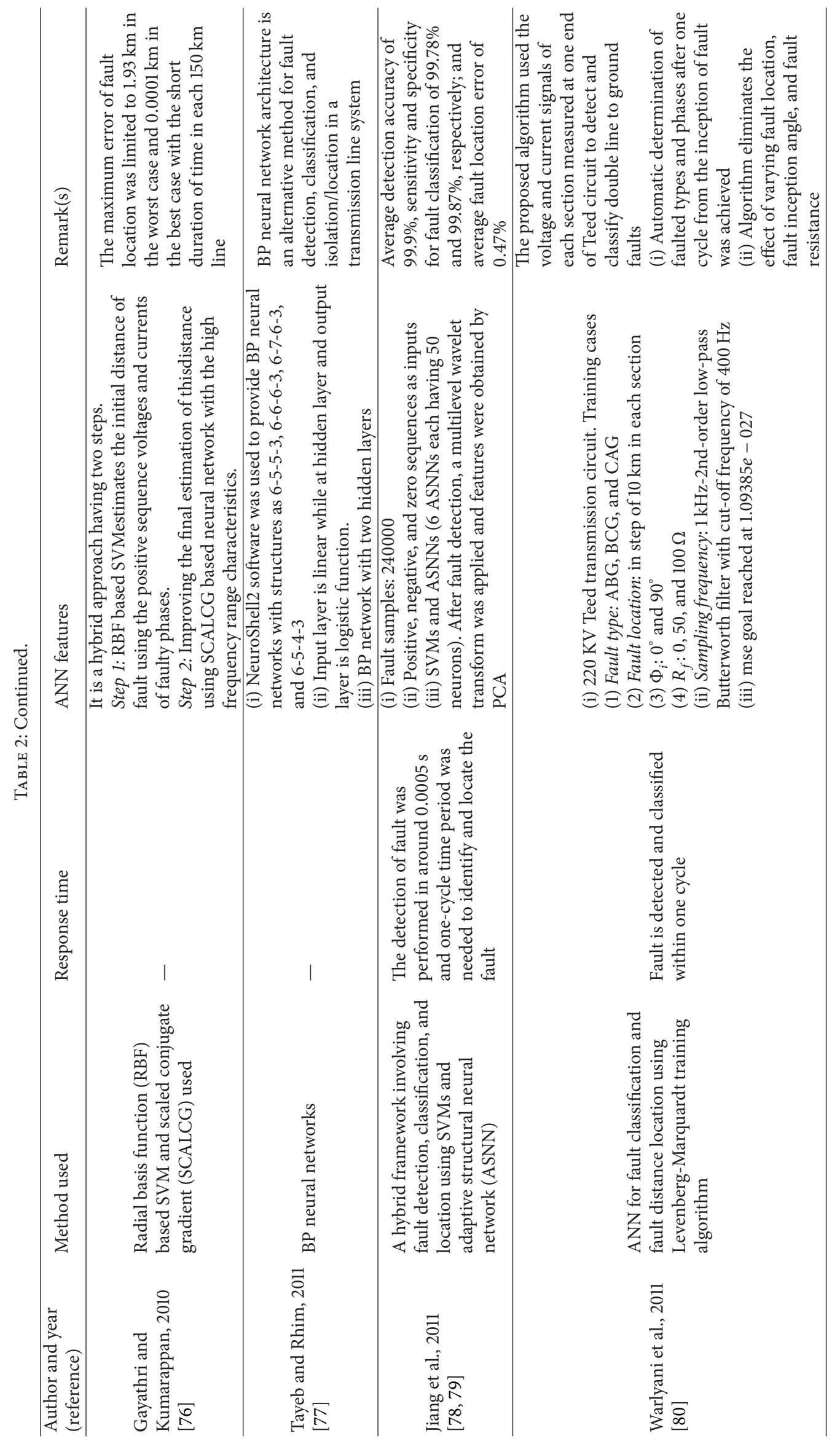




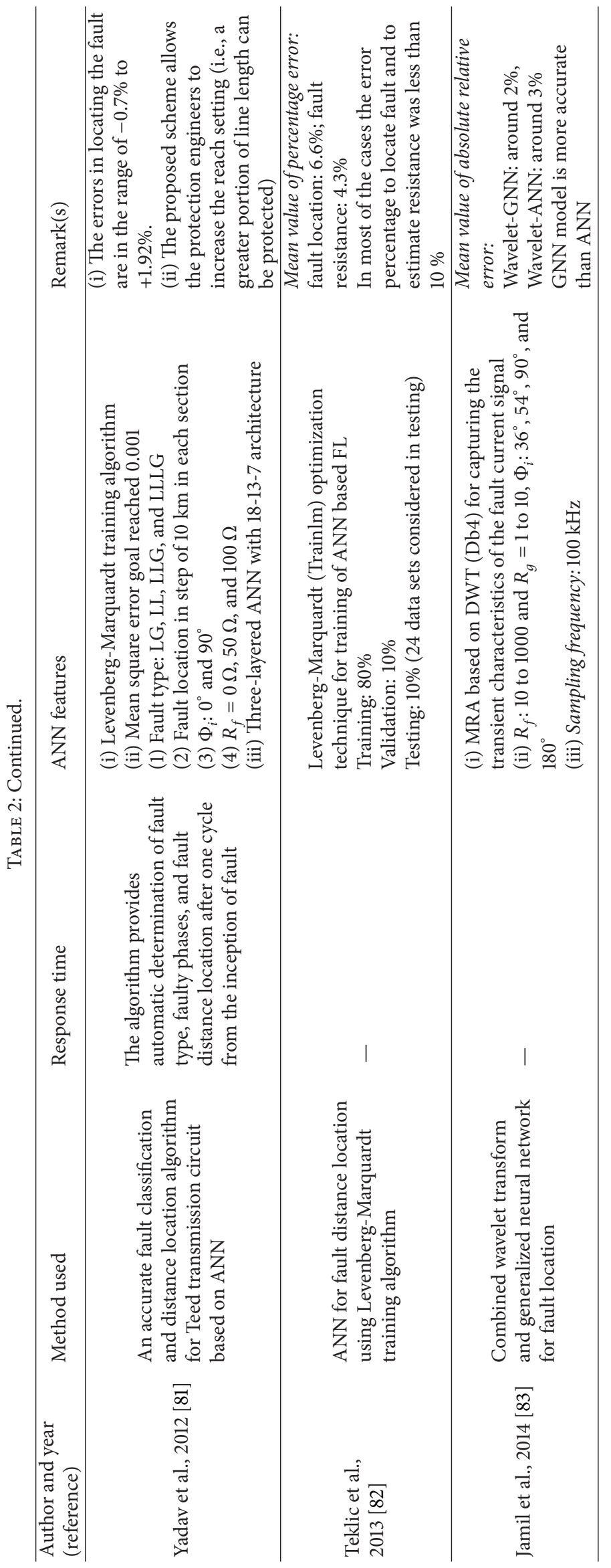




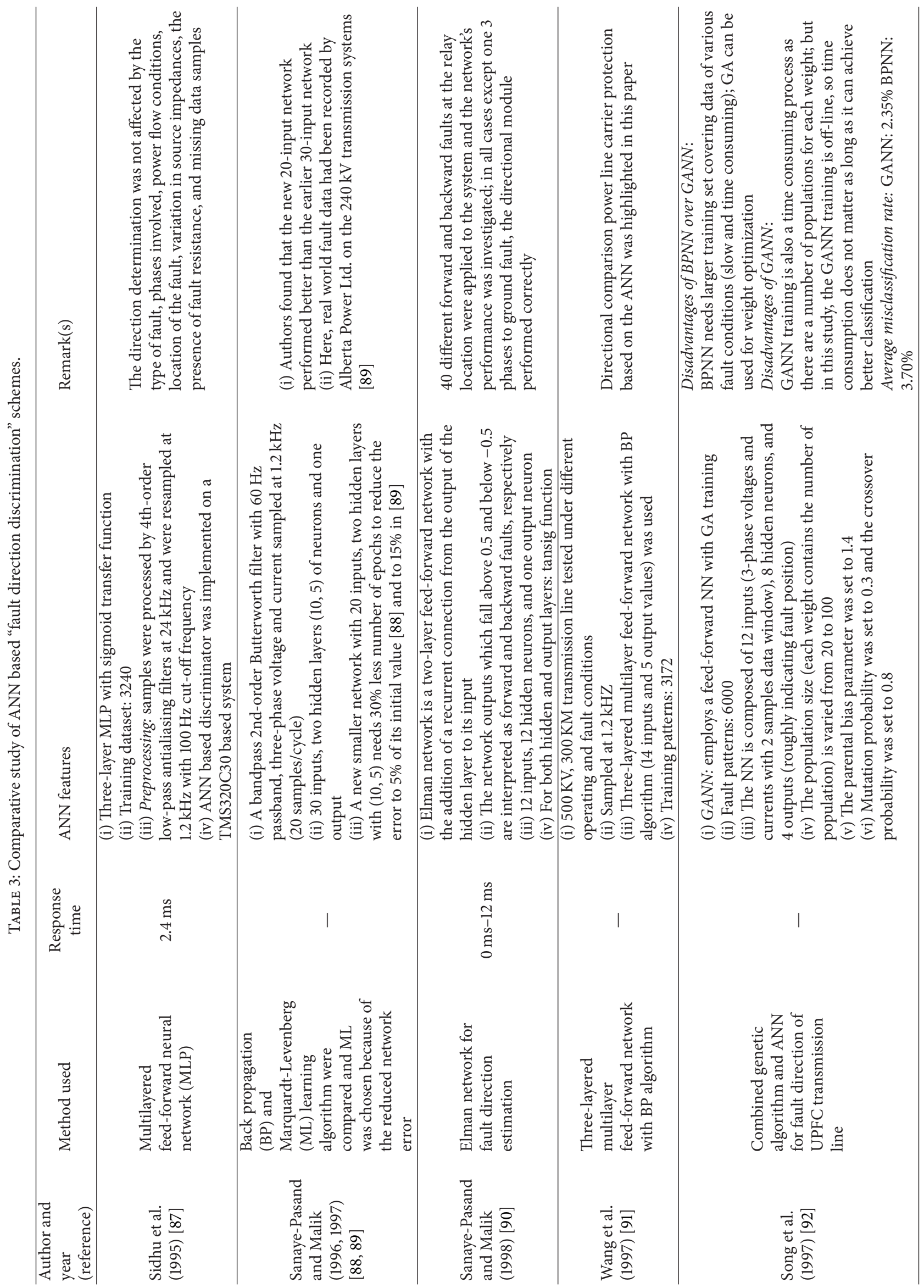




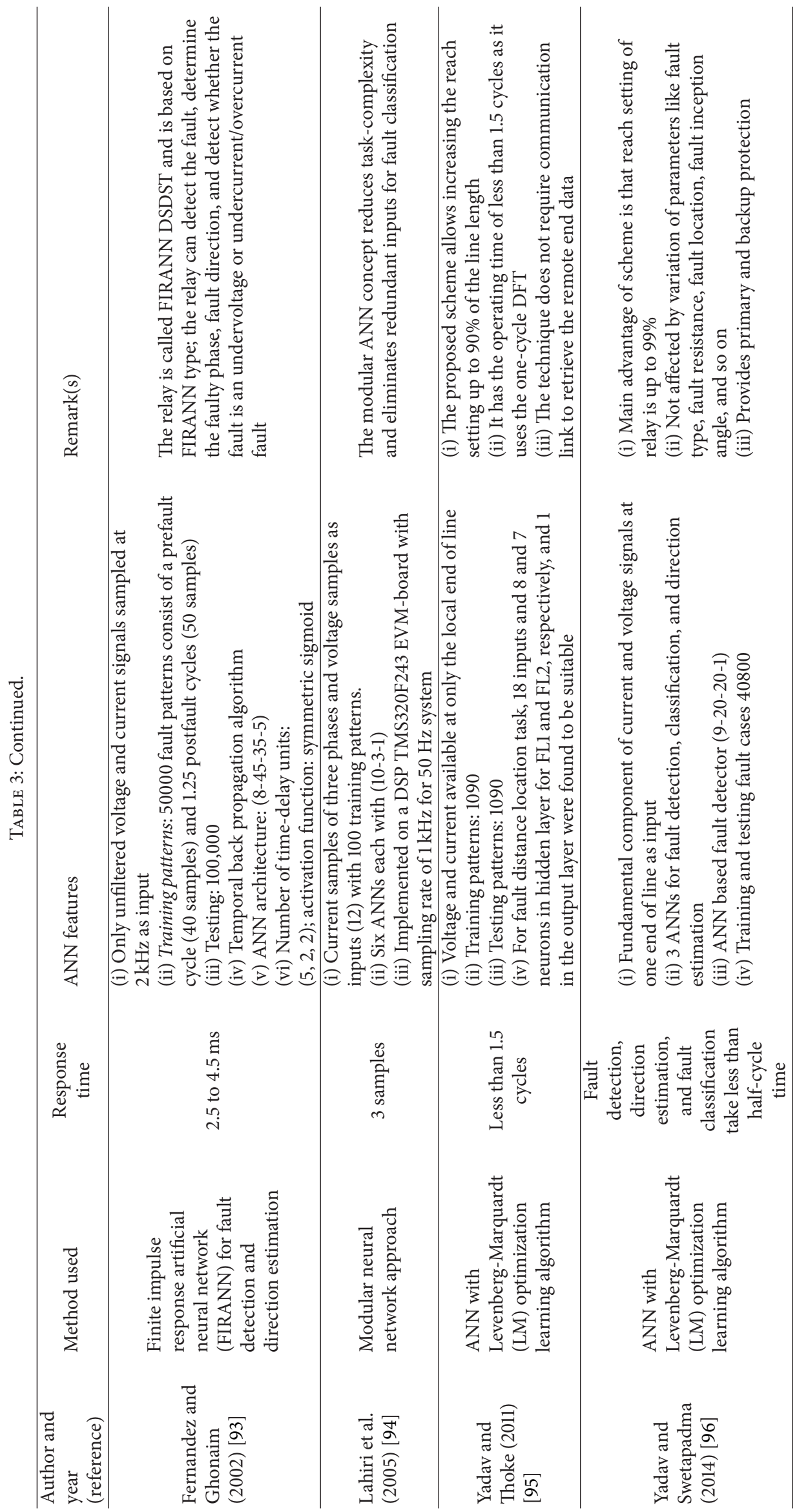




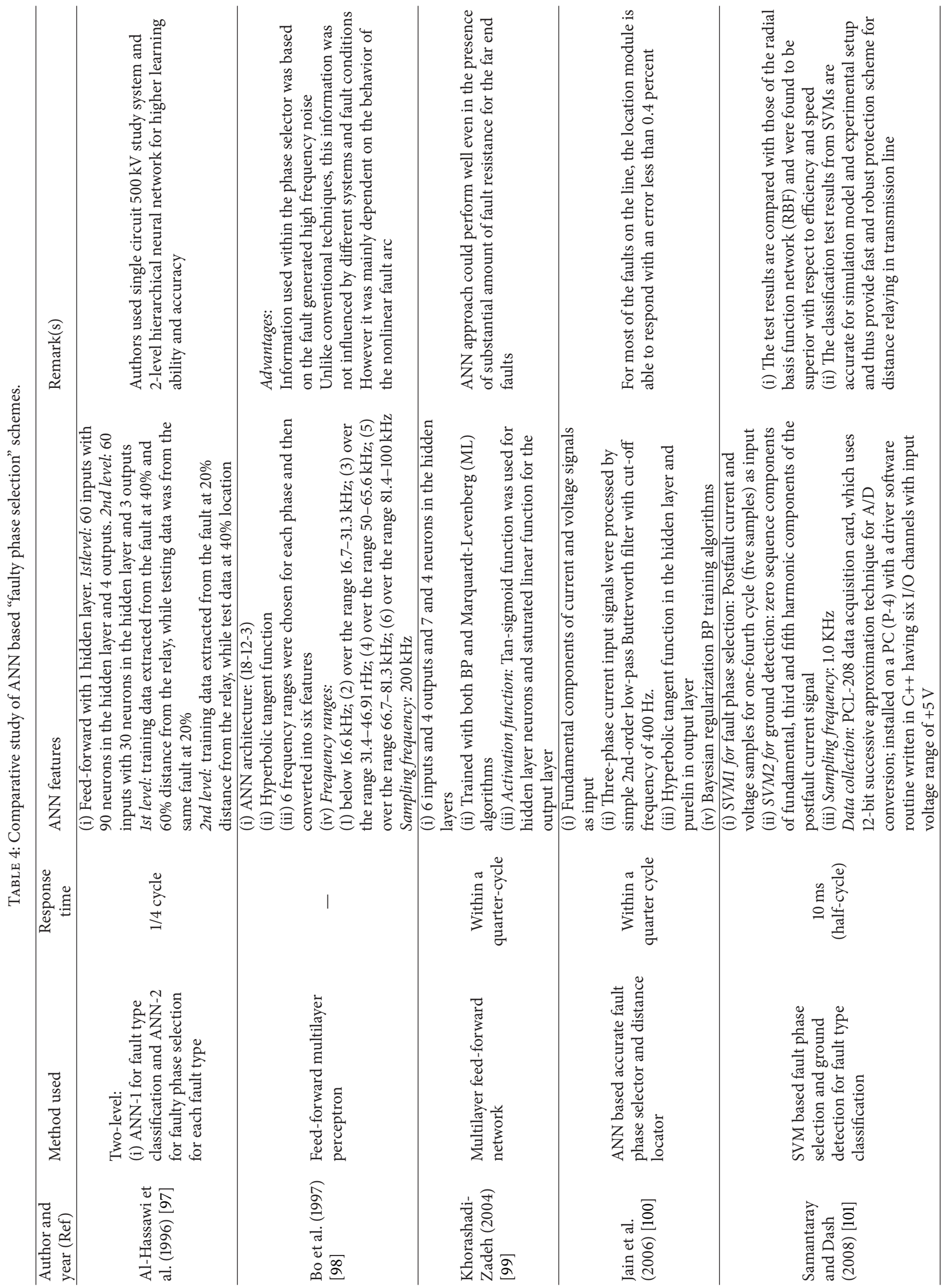




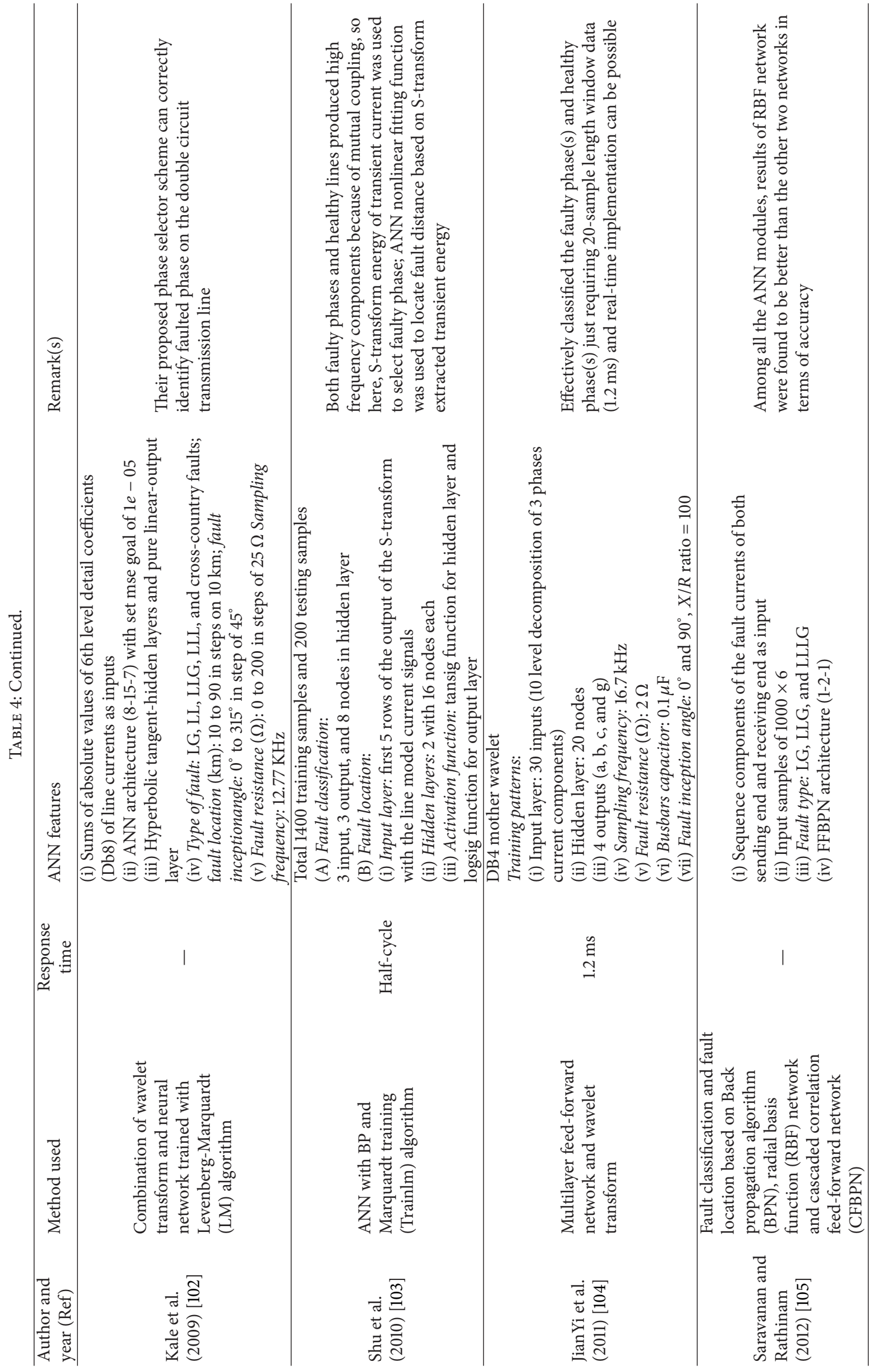


[80], Yadav et al. [81], Teklic et al. [82], and Jamil et al. [83]. A comparative study of different ANN based fault detection, classification, and location schemes is given in Table 2 highlighting the methods used, their response time, and ANN features along with remarks.

5.3. Studies on "Fault Direction Discrimination". Fault direction estimation on transmission line is very crucial for enhancing the performance of power system. Advancement of huge generating stations and highly interconnected power systems entails less fault clearing times. The approach of ANN has been positively utilized for the improvement of many of the standard functions that are operated in transmission lines. The accuracy of an electromechanical, static, or a microprocessor based distance relay is affected by different fault conditions and network configuration changes. Hence the direction of the fault should be discriminated to maintain the normal operation of the power system.

Dalstein et al. have used ANN method to estimate the fault location process by means of directional discrimination. They have proposed a neural network to estimate the direction of the fault $[84,85]$. Authors [86] employed neural network for designing two different fault direction discrimination modules for high speed transmission line and found that fault direction can be identified quickly and accurately from their results. Table 3 highlights the different schemes [87-96] used for fault direction estimation with its response time and features of ANN along with remarks.

5.4. Studies on "Faulty Phase Selection". Fault phase selection, an imperative part of fault diagnosis, is carried out by measuring faulty line parameters. Different power system faults such as LG, LL, LLG, LLL, and LLLG on a protected transmission line should be detected, classified, and located and faulty phase should be selected swiftly for performing the normal system operation. The summarized study of different ANN based fault phase selection schemes is given in Table 4 highlighting the methods used, their response time, and ANN features along with remarks [97-105].

\section{Conclusion}

There are widespread applications of ANN in power system protection, but this paper intensively analyzed few of them. Novel tools and techniques are preferred to maintain power system reliability and security within a satisfactory level for improvement of the performance of digital protective relays, renovation of power industry, and stability of the transmission lines. ANN is found to be robust, accurate, and efficient approach for transmission line fault detection, classification, localization, direction discrimination, and faulty phase selection. A comparative study of different schemes for fault detection, fault classification, fault location, fault direction estimation, and faulty phase selection has been discussed in detail. An extensive survey of the published studies on the subject of ANN application to transmission line protection is specified in this paper which will be beneficial for researchers for further research and development in this field.

\section{Conflict of Interests}

The authors declare that there is no conflict of interests regarding the publication of this paper.

\section{Acknowledgments}

The authors acknowledge the financial support of Chhattisgarh Council of Science \& Technology (CGCOST) for funding the Project no. 8062/CGCOST/MRP/13, dtd. 27.12.2013. They also thank the Department of Electrical Engineering, National institute of Technology, Raipur, for providing the research facilities to conduct this project.

\section{References}

[1] AIEE Committee Report, "Power system fault control," Transactions of the American Institute of Electrical Engineers, vol. 70, no. 1, pp. 410-417, 1951.

[2] W. A. Lewis, "Principles of high-speed relaying," Westinghouse Engineer, vol. 3, pp. 131-134, 1943.

[3] M. F. Hebb Jr. and J. T. Logan, "Relay modernization program releases latent transmission capacity," in Proceedings of the AIEE District Conference, Paper 55-354.

[4] National Electrical Manufacturers Association, "Standards for power circuit breakers," Tech. Rep. SG4-1954, National Electrical Manufacturers Association, New York, NY, USA, 1954.

[5] Wikipedia, 2014, http://www.wikipedia.org/.

[6] S. B. Crary, Power System Stability, vol. 2, John Wiley \& Sons, New York, NY, USA, 1947.

[7] Y. Dash and S. K. Dubey, "Quality prediction in object oriented system by using ANN: a brief survey," International Journal of Advanced Research in Computer Science and Software Engineering, vol. 2, no. 2, 2012.

[8] S. K. Dubey, A. Rana, and Y. Dash, "Maintainability prediction of object oriented software system by multilayer perceptron model," ACM SIGSOFT Software Engineering Notes, vol. 37, no. 5, pp. 1-4, 2012.

[9] Y. Dash, S. K. Dubey, and A. Rana, "Maintainability assessment of object oriented software system by using artificial neural network approach," International Journal of Soft Computing and Engineering, vol. 2, no. 2, pp. 420-423, 2012.

[10] E. Chan, "A application of neural network computing in intelligent alarm processing," in Proceedings of the Power Industry Computer Application Conference, pp. 246-251, IEEE, Seattle, Wash, USA, 1989.

[11] T. Bi, Y. Ni, and F. Wu, "A novel neural network approach for fault section estimation," Proceddings of the CSEE, vol. 22, no. 2, pp. 73-78, 2002.

[12] G. Cardoso Jr., J. G. Rolim, and H. H. Zürn, "Application of neural-network modules to electric power system fault section estimation," IEEE Transactions on Power Delivery, vol. 19, no. 3, pp. 1034-1041, 2004.

[13] S. A. Khaparde, P. B. Kale, and S. H. Agarwal, "Applications of artificial neural networks in protective relaying of transmission lines," in Proceedings of the 1st International Forum of Neural Networks to Power Systems, pp. 122-126, Seattle, Wash, USA, 1991. 
[14] S. A. Khaparde, N. Warke, and S. H. Agarwal, "Adaptive relaying using artificial neural network," in Proceedings of the 2nd International Forum on Applications of Neural Networks to Power Systems (ANNPS '93), pp. 447-452, Yokohama, Japan, 1993.

[15] A. A. Girgis, D. G. Hart, and W. L. Peterson, "A new fault location technique for two- and three-terminal lines," IEEE Transactions on Power Delivery, vol. 7, no. 1, pp. 98-107, 1992.

[16] W. Qi, G. W. Swift, P. G. McLaren, and A. V. Castro, "Artificial neural network application to distance protection," in Proceedings of the International Conference on Intelligent Systems Applications to Power Systems (ISAP'96), pp. 226-230, February 1996.

[17] S. A. Khaparde, "An adaptive approach in distance protection using an artificial neural network," Fuel and Energy Abstracts, vol. 37, no. 6, p. 430, 1996.

[18] L. L. Lai, "Application of Neural Networks to Fault Classification and Protection," in Proceedings of the 4th International Conference on Advances in Power System Control, Operation and Management, Hong Kong, November 1997.

[19] D. V. Coury and D. C. Jorge, "Artificial neural network approach to distance protection of transmission lines," IEEE Transactions on Power Delivery, vol. 13, no. 1, pp. 102-108, 1998.

[20] K. R. Cho, Y. C. Kang, S. S. Kim, J. K. Park, S. H. Kang, and K. H. Kim, "An ANN based approach to improve the speed of a differential equation based distance relaying algorithm," IEEE Transactions on Power Delivery, vol. 14, no. 2, pp. 349-357, 1999.

[21] F. Zahra, B. Jeyasurya, and J. E. Quaicoe, "High-speed transmission line relaying using artificial neural networks," Electric Power Systems Research, vol. 53, no. 3, pp. 173-179, 2000.

[22] Z. Chen and J.-C. Maun, "Artificial neural network approach to single-ended fault locator for transmission lines," IEEE Transactions on Power Systems, vol. 15, no. 1, pp. 370-375, 2000.

[23] G. K. Purushothama, A. U. Narendranath, D. Thukaram, and K. Parthasarathy, "ANN applications in fault locators," International Journal of Electrical Power and Energy Systems, vol. 23, no. 6, pp. 491-506, 2001.

[24] M. M. Tawfik and M. M. Morcos, "ANN-based techniques for estimating fault location on transmission lines using prony method," IEEE Transactions on Power Delivery, vol. 16, no. 2, pp. 219-224, 2001.

[25] S. Ekici, S. Yildirim, and M. Poyraz, "A transmission line fault locator based on Elman recurrent networks," Applied Soft Computing Journal, vol. 9, no. 1, pp. 341-347, 2009.

[26] R. Venkatesan and B. Balamurugan, "A real-time hardware fault detector using an artificial neural network for distance protection," IEEE Transactions on Power Delivery, vol. 16, no. 1, pp. 7582, 2001.

[27] A. K. Pradhan, P. K. Dash, and G. Panda, "A fast and accurate distance relaying scheme using an efficient radial basis function neural network," Electric Power Systems Research, vol. 60, no. 1, pp. 1-8, 2001.

[28] P. K. Dash, A. K. Pradhan, and G. Panda, "Application of minimal radial basis function neural network to distance protection," IEEE Transactions on Power Delivery, vol. 16, no. 1, pp. 68-74, 2001.

[29] E. A. Feilat and K. Al-Tallaq, "A new approach for distance protection using artificial neural network," in Proceedings of the 39th International Universities Power Engineering Conference (UPEC '04), vol. 1, pp. 473-477, September 2004.
[30] R. C. D. Santos and E. C. Senger, "Transmission lines distance protection using artificial neural networks," International Journal of Electrical Power and Energy Systems, vol. 33, no. 3, pp. 721730, 2011.

[31] A. P. Vaidya and P. A. Venikar, "ANN based distance protection of long transmission lines by considering the effect of fault resistance," in Proceedings of the International Conference on Advances in Engineering, Science and Management (ICAESM '12), pp. 590-594, Tamil Nadu, India, March 2012.

[32] J. R. de Carvalho, D. V. Coury, C. A. Duque, and B. F. Paula, "A new transmission line protection approach using cumulants and artificial neural networks," Journal of Control, Automation and Electrical Systems, vol. 25, no. 2, pp. 237-251, 2014.

[33] S.-W. Lim and R. A. Shoureshi, "Neural-based monitoring system for health assessment of electric transmission lines," in Proceedings of the American Control Conference, vol. 3, pp. 22702275, Denver, Colo, USA, June 2003.

[34] T. Dalstein and B. Kulicke, "Neural network approach to fault classification for high speed protective relaying," IEEE Transactions on Power Delivery, vol. 10, no. 2, pp. 1002-1009, 1995.

[35] M. Kezunovic and I. Rikalo, "Detect and classify faults using neural nets," IEEE Computer Applications in Power, vol. 9, no. 4, pp. 42-47, 1996.

[36] M. Kezunović, I. Rikalo, and D. J. Šobajić, "High-speed fault detection and classification with neural nets," Electric Power Systems Research, vol. 34, no. 2, pp. 109-116, 1995.

[37] E. Vazquez, H. J. Altuve, and O. L. Chacon, "Neural network approach to fault detection in electric power systems," in Proceedings of the IEEE International Conference on Neural Networks, vol. 4, pp. 2090-2095, Washington, DC, USA, June 1996.

[38] E. Vazquez, O. L. Chacon, and H. J. Altuve, "Neural-networkbased fault detector for transmission line protecirion," in Proceedings of the Mexico-USA Collaboration in Intelligent Systems Technologies (ISAI/IFIS '96), pp. 180-185, November 1996.

[39] B. H. Chowdhury and K. Wang, "Fault classification using Kohonen feature mapping," in Proceedings of the International Conference on Intelligent Systems Applications to Power Systems (ISAP '96), pp. 194-198, February 1996.

[40] F. N. Chowdhury and J. L. Aravena, "A modular methodology for fast fault detection and classification in power systems," IEEE Transactions on Control Systems Technology, vol. 6, no. 5, pp. 623-634, 1998.

[41] H. Wang and W. W. L. Keerthipala, "Fuzzy-neuro approach to fault classification for transmission line protection," IEEE Transactions on Power Delivery, vol. 13, no. 4, pp. 1093-1104, 1998.

[42] W. W. L. Keerthipala, H. Wang, and C. Tat Wai, "On-line testing of a fuzzy-neuro based protective relay using a real-time digital simulator," in Proceedings of the IEEE Power Engineering Society Winter Meeting, vol. 3, pp. 1917-1922, January 2000.

[43] S. Vasilic and M. Kezunovic, "Fuzzy ART neural network algorithm for classifying the power system faults," IEEE Transactions on Power Delivery, vol. 20, no. 2, pp. 1306-1314, 2005.

[44] N. Zhang and M. Kexunovic, "Coordinating fuzzy ART neural networks to improve transmission line fault detection and classification," in Proceedings of the IEEE Power Engineering Society General Meeting, vol. 1, pp. 734-740, IEEE, June 2005.

[45] K. M. Silva, B. A. Souza, and N. S. D. Brito, "Fault detection and classification in transmission lines based on wavelet transform and ANN," IEEE Transactions on Power Delivery, vol. 21, no. 4, pp. 2058-2063, 2006. 
[46] H. Zheng-you, C. Xiaoqing, and L. Guoming, "Wavelet entropy measure definition and its application for transmission line fault detection and identification; (Part I: Definition and Methodology)," in Proceedings of the International Conference on Power System Technology (POWERCON '06), pp. 1-6, Chongqing, China, October 2006.

[47] F. Martín, J. A. Aguado, M. Medina, and J. Muñoz, "Classification of faults in double circuit lines using wavelet transforms," in Proceedings of the IEEE International Conference on Industrial Technology (ICIT '08), pp. 1-6, Chengdu, China, April 2008.

[48] T. A. Kawady, A. E. Ibrahim, and A.-M. Taalab, "A gabor transform-based Universal fault detector for transmission lines," in Proceedings of the 12th International Middle East Power System Conference (MEPCON '08), pp. 265-269, March 2008.

[49] F. Mahmood, S. A. Qureshi, and M. Kamran, "Application of wavelet multi-resolution analysis \& perceptron neural networks for classification of transients on transmission line," in Proceedings of the Australasian Universities Power Engineering Conference (AUPEC '08), pp. 1-5, December 2008.

[50] M. Geethanjali and K. S. Priya, "Combined wavelet transforms and neural network (WNN) based fault detection and classification in transmission lines," in Proceedings of the International Conference on Control, Automation, Communication and Energy Conservation (INCACEC '09), pp. 1-7, June 2009.

[51] C. Pothisarn and A. Ngaopitakkul, "Discrete wavelet transform and back-propagation neural networks algorithm for fault classification on transmission line," in Proceedings of the Transmission and Distribution Conference and Exposition: Asia and Pacific, T and D Asia, pp. 1-4, Seoul, Republic of Korea, October 2009.

[52] A. Abdollahi and S. Seyedtabaii, "Comparison of fourier \& wavelet transform methods for transmission line fault classification," in Proceedings of the 4th International Power Engineering and Optimization Conference (PEOCO '10), pp. 579-584, Shah Alam, Malaysia, June 2010.

[53] A. Jain, A. S. Thoke, R. N. Patel, and E. Koley, "Intercircuit and cross-country fault detection and classification using artificial neural network," in Proceedings of the Annual IEEE India Conference: Green Energy, Computing and Communication (INDICON '10), pp. 1-4, Kolkata, India, December 2010.

[54] A. Jain, A. S. Thoke, and R. N. Patel, "Fault classification of double circuit transmission line using artificial neural network," International Journal of Electrical Systems Science and Engineering, vol. 1, no. 4, pp. 750-755, 2008.

[55] A. Jain, A. S. Thoke, and R. N. Patel, "Classification of single line to ground faults on double circuit transmission line using ANN," International Journal of Computer and Electrical Engineering, vol. 1, no. 2, pp. 197-203, 2009.

[56] A. Jain, A. S. Thoke, P. K. Modi, and R. N. Patel, "Classification and location of single line to ground faults in double circuit transmission lines using artificial neural networks," International Journal of Power and Energy Conversion, vol. 2, no. 2, pp. 109-125, 2010.

[57] A. Yadav, "Comparison of single and modular ann based fault detector and classifier for double circuit transmission lines," International Journal of Engineering, Science and Technology, vol. 4, no. 2, pp. 122-136, 2012.

[58] A. Jain, "Artificial neural network-based fault distance locator for double-circuit transmission lines," Advances in Artificial Intelligence, vol. 2013, Article ID 271865, 12 pages, 2013.

[59] J. Chen and R. K. Aggarwal, "A new approach to EHV transmission line fault classification and fault detection based on the wavelet transform and artificial intelligence," in Proceedings of the IEEE Power and Energy Society General Meeting, pp. 1-8, July 2012.

[60] M. Ben Hessine, H. Jouini, and S. Chebbi, "Fault detection and classification approaches in transmission lines using artificial neural networks," in Proceedings of the 17th IEEE Mediterranean Electrotechnical Conference (MELECON '14), pp. 515519, Beirut, Lebanon, April 2014.

[61] Z. He, S. Lin, Y. Deng, X. Li, and Q. Qian, “A rough membership neural network approach for fault classification in transmission lines," International Journal of Electrical Power and Energy Systems, vol. 61, pp. 429-439, 2014.

[62] E. Koley, A. Jain, A. S. Thoke, S. Ghosh, and A. Jain, "Detection and classification of faults on six phase transmission line using ANN," in Proceedings of the International Conference on Computer and Communication Technology (ICCCT '11), paper no. 334, pp. 100-103, Motilal Nehru National Institute of Technology (MNNIT), Allahabad, India, September 2011.

[63] E. Koley, A. Yadav, and A. S. Thoke, "Six phase to ground fault detection and classification of transmission line using ANN," International Journal of Computer Applications, vol. 41, no. 4, pp. 6-10, 2012.

[64] E. Koley, A. Yadav, A. S. Thoke, and T. Kodiyar, "Protection of six phase transmission line against phase to phase fault," in Proceedings of the International Conference on Advances in Computer, Electronics and Electrical Engineering, Paper no. 714, pp. 25-27, Mumbai, India, March 2012.

[65] E. Koley, A. Yadav, and A. S. Thoke, "A new single-ended artificial neural network-based protection scheme for shunt faults in six-phase transmission line," International Transactions on Electrical Energy Systems, 2014.

[66] R. Kumar, E. Koley, A. Yadav, and A. S. Thoke, "Fault classification of phase to phase fault in six phase transmission line using Haar wavelet and ANN," in Proceedings of the International Conference on Signal Processing and Integrated Networks (SPIN '14), pp. 5-8, Amity School Of Engineering and Technology, Noida, India, Feburary 2014.

[67] N. Amjady, "On-line fault diagnosis of power systems by a new expert system," in Proceedings of the 11th Canadian Conference on Electrical and Computer Engineering (CCECE '98), vol. 2, pp. 731-733, May 1998.

[68] M. Oleskovicz, D. V. Coury, and R. K. Aggarwal, "A complete scheme for fault detection, classification and location in transmission lines using neural networks," in Proceedings of the IEEE 7th International Conference on Developments in Power System Protection (DSP '01), pp. 335-338, 2001.

[69] D. V. Coury, M. Oleskovicz, and R. K. Aggarwal, "An ANN routine for fault detection, classification, and location in transmission lines," Electric Power Components and Systems, vol. 30, no. 11, pp. 1137-1149, 2002.

[70] M. F. Othman, M. Mahfouf, and D. A. Linkens, "Transmission lines fault detection, classification and location using an intelligent power system stabiliser," in Proceedings of the IEEE International Conference on Electric Utility Deregulation, Restructuring and Power Technologies (DRPT '04), vol. 1, pp. 360-365, April 2004.

[71] R. N. Mahanty and P. B. Dutta Gupta, "Application of RBF neural network to fault classification and location in transmission lines," IEE Proceedings: Generation, Transmission and Distribution, vol. 151, no. 2, pp. 201-212, 2004.

[72] J. Gracia, A. J. Mazón, and I. Zamora, "Best ANN structures for fault location in single- and double-circuit transmission lines," 
IEEE Transactions on Power Delivery, vol. 20, no. 4, pp. 23892395, 2005.

[73] X. Lin, P. Mao, H. Weng, B. Wang, Z. Q. Bo, and A. Klimek, "Study on fault location for high voltage overhead transmission lines based on neural network system," in Proceedings of the International Conference on Intelligent Systems Applications to Power Systems (ISAP '07), pp. 1-5, November 2007.

[74] A. Jain, A. S. Thoke, E. Koley, and R. N. Patel, "Fault classification and fault distance location of double circuit transmission lines for phase to phase faults using only one terminal data," in Proceedings of the International Conference on Power Systems (ICPS '09), pp. 1-6, December 2009.

[75] M. F. Othman and H. A. Amari, "Online fault detection for power system using wavelet and PNN," in Proceedings of the IEEE 2nd International Power and Energy Conference (PECon '08), pp. 1644-1648, December 2008.

[76] K. Gayathri and N. Kumarappan, "Accurate fault location on EHV lines using both RBF based support vector machine and SCALCG based neural network," Expert Systems with Applications, vol. 37, no. 12, pp. 8822-8830, 2010.

[77] E. B. M. Tayeb and O. A. A. A. Rhim, "Transmission line faults detection, classification and location using artificial neural network," in Proceedings of the International Conference and Utility Exhibition on Power and Energy Systems: Issues and Prospects for Asia (ICUE '11), pp. 1-5, Pattaya, Thailand, September 2011.

[78] J.-A. Jiang, C.-L. Chuang, Y.-C. Wang et al., "A hybrid framework for fault detection, classification, and location-part I: concept, structure, and methodology," IEEE Transactions on Power Delivery, vol. 26, no. 3, pp. 1988-1998, 2011.

[79] J.-A. Jiang, C.-L. Chuang, Y.-C. Wang et al., "A hybrid framework for fault detection, classification, and location-part II: implementation and test results," IEEE Transactions on Power Delivery, vol. 26, no. 3, pp. 1999-2008, 2011.

[80] P. Warlyani, A. Jain, A. S. Thoke, and R. N. Patel, "Fault classification and faulty section identification in teed transmission circuits using ANN," International Journal of Computer and Electrical Engineering, vol. 3, no. 6, pp. 807-811, 2011.

[81] A. Yadav, P. Warlyani, and A. S. Thoke, "Fault classification, distance location and faulty section identification in teed transmission circuits using artificial neural network," International Journal of Computer Applications, vol. 47, no. 15, pp. 19-25, 2012.

[82] L. Teklic, B. Filipovic-Grcic, and I. Pavicic, "Artificial neural network approach for locating faults in power transmission system," in Proceedings of the EUROCON Conference, pp. 14251430, IEEE, July 2013.

[83] M. Jamil, A. Kalam, A. Q. Ansari, and M. Rizwan, "Generalized neural network and wavelet transform based approach for fault location estimation of a transmission line," Applied Soft Computing Journal, vol. 19, pp. 322-332, 2014.

[84] T. Dalstein, "For an electric power supply network," Patent Application, 1993, http://www.google.com/patents/US5854590.

[85] T. Dalstein, D. J. Sobajic, B. Kulicke, and Y. H. Pao, "Neural network approach to fault direction identification in electric power systems," in Proceedings of the 25th Annual North American Power Symposium, pp. 290-299, Howard University, Washington, DC, USA, October 1993.

[86] M. Sanaye-Pasand and O. P. Malik, "Neural network-based fault direction discrimination for high-speed transmission line protection," Electric Power Components and Systems, vol. 29, no. 8, pp. 757-770, 2001.

[87] T. S. Sidhu, H. Singh, and M. S. Sachdev, "Design, implementation and testing of an artificial neural network based fault direction discriminator for protecting transmission lines," IEEE Transactions on Power Delivery, vol. 10, no. 2, pp. 697-703, 1995.

[88] M. Sanaye-Pasand and O. P. Malik, "Power transmission lines fault direction estimation using artificial neural networks," in Proceedings of the Canadian Conference on Electrical and Computer Engineering, vol. 2, pp. 758-761, May 1996.

[89] M. Sanaye-Pasand and O. P. Malik, "Performance evaluation of a new transmission line directional module using field data," in Proceedings of the Communications, Power and Computing Conference (WESCANEX '97), pp. 197-201, IEEE, May 1997.

[90] M. Sanaye-Pasand and O. P. Malik, "High speed transmission system directional protection using an Elman network," IEEE Transactions on Power Delivery, vol. 13, no. 4, pp. 1040-1045, 1998.

[91] W. Gang, H. Jiali, L. Yao, Y. Xiaodan, and L. Zhongpu, "Neural network application in directional comparison carrier protection of EHV transmission lines," in Proceedings of the 4th International Conference on Advances in Power System Control, Operation and Management (APSCOM '97), pp. 89-94, Hong Kong, November 1997.

[92] Y. H. Song, A. T. Johns, Q. Y. Xuan, and J. Y. Liu, "Genetic algorithm based neural networks applied to fault classification for EHV transmission lines with a UPFC," in Proceedings of the 6th International Conference on Developments in Power System Protection, Conference Publication No. 434, pp. 278-281, Nottingham, UK, March 1997.

[93] Á. L. O. Fernandez and N. K. I. Ghonaim, "A novel approach using a FIRANN for fault detection and direction estimation for high-voltage transmission lines," IEEE Transactions on Power Delivery, vol. 17, no. 4, pp. 894-900, 2002.

[94] U. Lahiri, A. K. Pradhan, and S. Mukhopadhyaya, "Modular neural network-based directional relay for transmission line protection," IEEE Transactions on Power Systems, vol. 20, no. 4, pp. 2154-2155, 2005.

[95] A. Yadav and A. S. Thoke, "Transmission line fault distance and direction estimation using artificial neural network," International Journal of Engineering, Science and Technology, vol. 3, no. 8, pp. 110-121, 2011.

[96] A. Yadav and A. Swetapadma, "Improved first zone reach setting of artificial neural network-based directional relay for protection of double circuit transmission lines," IET Generation, Transmission and Distribution, vol. 8, no. 3, pp. 373-388, 2014.

[97] W. M. Al-Hassawi, N. H. Abbasi, and M. M. Mansour, "A neuralnetwork-based approach for fault classification and faulted phase selection," in Proceedings of the Electrical and Computer Engineering Canadian Conference, vol. 1, pp. 384-387, May 1996.

[98] Z. Q. Bo, R. K. Aggarwal, A. T. Johns, H. Y. Li, and Y. H. Song, "A new approach to phase selection using fault generated high frequency noise and neural networks," IEEE Transactions on Power Delivery, vol. 12, no. 1, pp. 106-113, 1997.

[99] H. Khorashadi-Zadeh, "Artificial neural network approach to fault classification for double circuit transmission lines," in Proceedings of the Transmission and Distribution Conference and Exposition: Latin America, pp. 859-862, IEEE/PES, November 2004.

[100] A. Jain, V. S. Kale, and A. S. Thoke, "Application of artificial neural networks to transmission line faulty phase selection and fault distance location," in Proceedings of the IASTED International Conference "Energy and Power System", pp. 262-267, Chiang Mai, Thailand, 2006. 
[101] S. R. Samantaray and P. K. Dash, “Transmission line distance relaying using machine intelligence technique," IET Generation, Transmission and Distribution, vol. 2, no. 1, pp. 53-61, 2008.

[102] V. S. Kale, S. R. Bhide, and P. P. Bedekar, "Faulted phase selection on double circuit transmission line using wavelet transform and neural network," in Proceedings of the International Conference on Power Systems (ICPS '09), pp. 1-6, Kharagpur, India, December 2009.

[103] H. Shu, Q. Wu, X. Wang, and X. Tian, "Fault phase selection and distance location based on ANN and S-transform for transmission line in triangle network," in Proceedings of the $3 \mathrm{rd}$ International Congress on Image and Signal Processing (CISP '10), pp. 3217-3219, Yantai, China, October 2010.

[104] C. JianYi, A. Raj, and L. Yuping, "New algorithm for EHV transmission line faulted-phase selection based on wavelet transforms and artificial intelligence," in Proceedings of the International Conference on Advanced Power System Automation and Protection (APAP '11), vol. 3, pp. 2374-2379, October 2011.

[105] N. Saravanan and A. Rathinam, "A comparitive study on ANN based fault location and classification technique for double circuit transmission line," in Proceedings of the 4th International Conference on Computational Intelligence and Communication Networks (CICN '12), pp. 824-830, November 2012. 

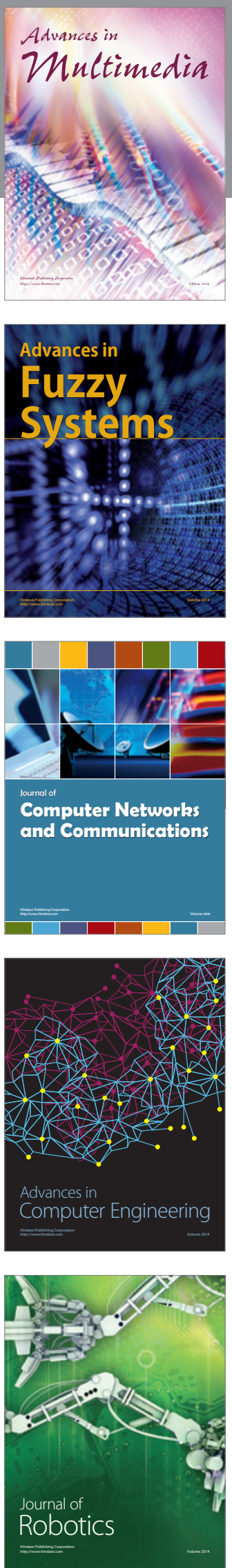

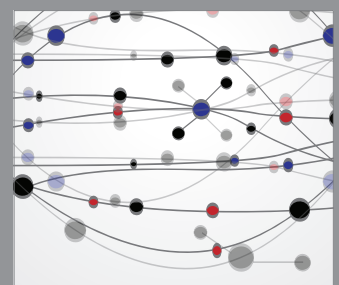

The Scientific World Journal
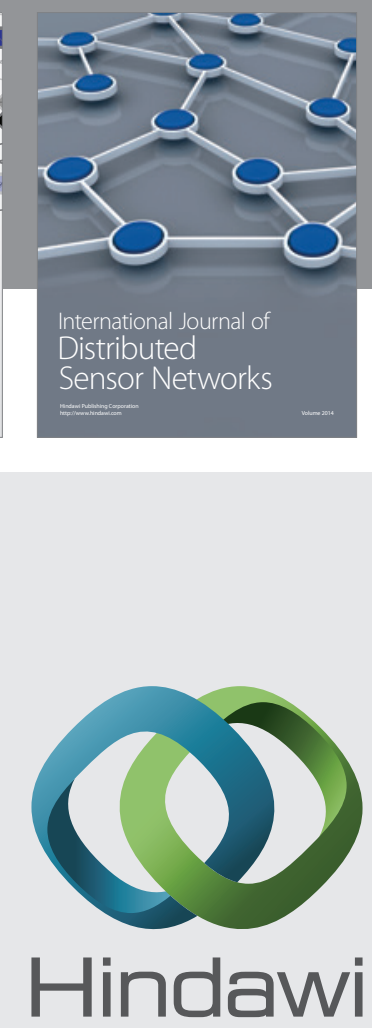

Submit your manuscripts at

http://www.hindawi.com
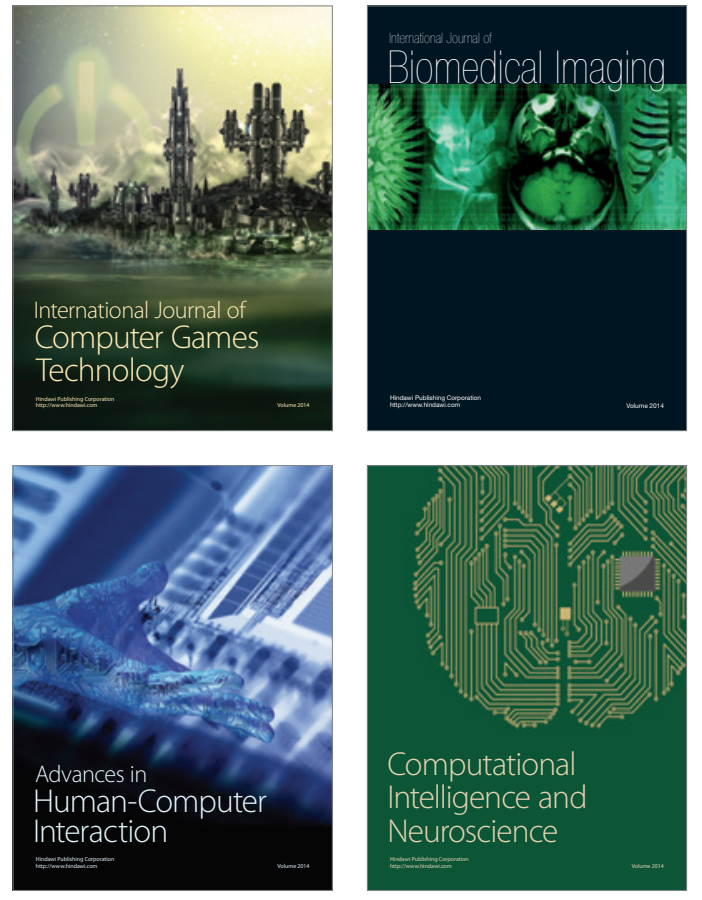
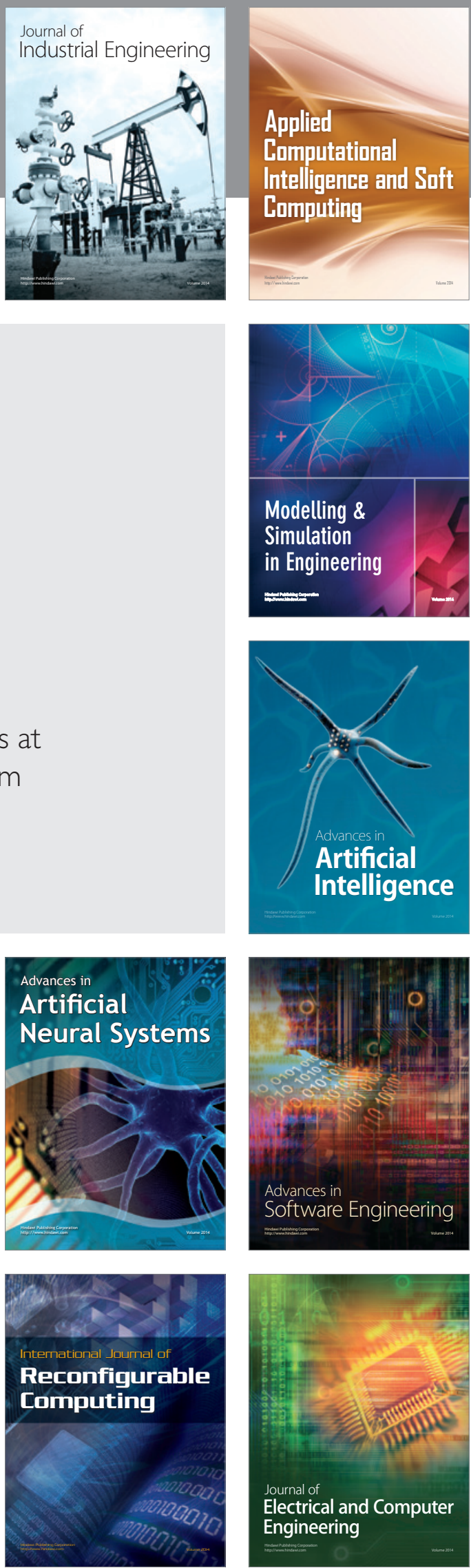